a case for such treatment in every variety of the disease, save perhaps in early cases which may go into remission spontaneously. Severe progressive rheumatoid arthritis provides many difficulties, but good results may be achieved, and in the long-standing crippled cases a combination of hormone therapy and orthopaedic treatment should be considered. They have also been impressed with the action of these drugs in scleroderma.

They conclude by stating that cortico-suprarenal hormone therapy has become a part of current practice for rheumatic conditions, both acute and chronic. They believe this to be warranted by the good results obtained, as compared to the ineffectiveness of other treatments, but feel disquieted because of the risks which are run when these drugs are used, and the uncertainty, as yet, of the long-term results. They stress the need for further research, particularly on mixed courses of cortisone and ACTH, the combination of chryso- and hormone therapy, and the local use of hydrocortisone. Oswald SAvage.

Les Rhumatismes en Médecine et dans la Société. By François Françon. 1952. Pp. 158. Editions Universelles, Paris.

This pocket edition was written with the intention of presenting rheumatism and its social aspects to the nonspecialist and to the cultured public.

The difficulties of a comprehensive classification of the rheumatic diseases are fully discussed in the introduction. The author, however, comes to a compromise by closely following the nomenclature recommended by the Rheumatism Commission of the French Ministry of Health (Paris, 1937), which is in many ways similar to the British classification suggested by the Royal College of Physicians in England. A useful table is then drawn under sixteen headings of the differences existing between the inflammatory and degenerative forms of rheumatism. Rheumatic fever (maladie de Bouillaud) is fully described, and its classical treatment by salicylates is discussed at length. The uses of ACTH and cortisone, and the prophylactic application of sulphonamides and penicillin, are briefly reviewed.

The chapter on the chronic forms of rheumatism gives to the reader a very good clinical picture of the different grades of rheumatoid arthritis, and treatment is discussed under the headings of internal medication, hygiene, diet, physical methods and orthopaedic measures. Though ACTH and cortisone may have their uses, gold remains the only drug which has stood the test of time.

Ankylosing spondylitis is included with Still's disease, and psoriatic arthritis as a sub-variety of rheumatoid arthritis. The plan of treatment here is slightly too rigid. The use of a full plaster of paris jacket for several months would not be approved by many rheumatologists.

Tuberculous rheumatism, a French concept, is described as a clinical entity, a point of view which is hardly accepted in England and is rejected in America.

The available space has not permitted a description of the degenerative types of arthritis, but for those who can read French, this excellent little book will be found to be a helpful reference for diagnosis and treatment.

M. H. L. Desmarais.
Report on an Enquiry into the Aetiological Factors associated with Rheumatoid Arthritis. Prepared by E. Lewis-Faning. Annals of the Rheumatic Diseases, Suppl. Vol. 9, 1950. British Medical Association, London. (7s. 6d.)

The Empire Rheumatism Council's statistical investigation into thirteen possible aetiological factors and thirteen clinical features of rheumatoid arthritis was published in a special supplement to the Annals of the Rheumatic Diseases in 1950. The investigation entailed the detailed study of 532 cases and 532 controls and the analysis of the results. It was a time-consuming and expensive venture, unique in this field, and produced many interesting facts, invaluable to further workers, though perhaps disappointing in the lack of dramatic findings. The conclusions of this report occasioned a spate of critical correspondence, disagreeing with the negative findings on certain aetiological factors. Such unexpected negative findings are very valuable, as they cause people to think again, though they do not prove that these factors have no effect whatsoever on the rheumatoid state.

The sex incidence was 100 males to 162 females, and it was found that the risk of developing the disease rose between the ages of 20 and 50 years. One of the surprising features was the absence of significant increase in psychological trauma in the patients as compared with the controls. There was no tendency to association with allergic disease, but focal sepsis was slightly more common in the rheumatoid group. A familial tendency was statistically proved. 24 per cent. of cases had commenced at the menopause. In considering working and home conditions, cold appeared as the only factor which tended to increase the risk of rheumatoid arthritis. Peripheral vascular instability occurred in nearly five times as many rheumatoids as controls, and frequently antedated the onset of the arthritis.

Undue fatigue, loss of weight, transient pains, and sweating were frequent prodromal symptoms. The onset was febrile in 14 per cent. and acute in 44 per cent.; 81 per cent. consulted their doctor within 3 months of the onset of symptoms. 12 per cent. of the rheumatoid cases had nodules. Only 7 per cent. had normal sedimentation rates.

These are some of the findings discussed in the Report, which should be studied in full. G. D. KerSLEY.

Rheumatic Fever. A symposium edited by Lewis Thomas. 1953. Pp. 349, 56 figs, 59 tables. University Press, Minnesota. Geoffrey Cumberlege, London. (80s.)

This is the report of the 29 papers and the consequent discussions which were contributed to a symposium held at the University of Minnesota in November, 1951. The publication of such symposia is an increasingly common practice which often lacks adequate justification. Sometimes the delay in publication is so great that the rapid advance of research has raced ahead of the contributors; sometimes the real merit of such symposia lies in the free exchange of ideas between writers in separate but contiguous fields and the printed page fails to recapture the 
value of such stimulating exchanges. This volume can, however, be unreservedly recommended. Many of the contributors, such as McQuarrie, Duckett Jones, G. E. Murphy, Ann Kuttner, M. J. Shapiro, and F. F. Schwentker, have already made substantial advances in our knowledge of rheumatic fever, and other writers whose names are unknown to the reviewer here make impressive contributions.

It is more than twenty years now since Alison Glover wrote of rheumatic fever as an obsolescent disease, and it is to his credit that time has proved his hopeful forecast false. For rheumatic fever is still an implacable and unconquered enemy of mankind. During the last six months there has been a marked recrudescence of acute rheumatism in children in areas where the disease has been quiescent for two or three years ; and it should be continuously remembered that as many hearts are being quietly crippled by one insidious attack as are damaged by overt rheumatism. These papers not only deal with the natural history, prophylaxis, and treatment of acute rheumatism; their especial value lies in their recognition that it is only by the elucidation of the peculiarities of the individual host that full understanding will be achieved.

Murphy gives a masterly review of the histopathology of rheumatic fever and advances the view that the Aschoff $\bar{\omega}$ bodies are formed from the damaged myocardial fibres. There is a useful paper by H. L. Hodes on non-rheumatic myocarditis, which emphasizes the non-progressive $\frac{}{0}$ nature of this cardiac damage compared with that of $\frac{\bar{C}}{\sigma}$ rheumatic fever. Several papers discuss the acute-phase $\overline{\bar{D}}$ reactions, including the measurement of hyaluronidase $\vec{\nabla}$ inhibitor, C-reactive proteins, and antibody responses, $\unrhd$ and demonstrate that, while such tests are of increasing value, they are not yet of specific diagnostic quality. $\vec{\circ}$ Dorfman contributes an enlightening paper on the biochemistry of connective tissue and rheumatic fever. $\overrightarrow{\vec{\omega}}$ It was news to the reviewer that the only mammalian organ which has been proved to contain hyaluronidase ฏ is the testis. Well-balanced surveys by Rammelkamp on 으 the prevention of rheumatic fever and by Shapiro on its $\vec{N}$ management conclude an admirable volume.

Douglas Hubble.

\section{NEW YORK RHEUMATISM ASSOCIATION}

\section{ANNUAL MEETING, 1953}

The Annual Meeting of the New York Rheumatism Association was held at the Cornell University Medical College, New York, on April 8, 1953. Dr. Charles Ragan presided, and the following papers were given:

Relationship of Sensitized Sheep Cell Reaction to Rheumatoid Arthritis. By Ronald W. Lamont-Havers (Presbyterian Hospital).

Long-Term Therapy of Rheumatoid Arthritis with PABA and Cortisone. By Leon L. Wiesel and A. Sidney Barrit (Brooklyn Hospital).

Altered Hepatic Function in Rheumatoid Arthritis; Effect of Butazolidin Therapy. By Jack R. Dordick and Hyman Bakst (Beth Israel Hospital).

Chordotomy in the Treatment of Osteo-Arthritis of the Hip. By Byron Stookey (Neurological Institute).
Absorptive Arthropathy. By Murray Silver and Otto Steinbrocker (Hospital for Joint Diseases).

Dissemination of Chronic Discoid Lupus Erythematosus. $\overrightarrow{\overrightarrow{\vec{D}}}$ By Jerome Simson (Third (New York University) Division, Bellevue Hospital).

The following officers and executive committee members were elected for 1953-54:

$\begin{array}{ll}\text { President: } & \text { Robert M. Lintz } \\ \text { Vice-President: } & \text { Jed H. Irvine } \\ \text { Secretary-Treasurer: } & \text { Bernard Rogoff } \\ \text { Executive Committee: }: & \text { Charles Ragan } \\ & \text { William Kammerer } \\ & \text { Robert L. Preston } \\ & \text { Edward F. Hartung } \\ & \text { Currier McEwen } \\ & \text { Charles M. Plotz }\end{array}$

\section{CORRIGENDUM}

Annals of the Rheumatic Diseases (1953), 12, 49. In the list of Officers of the Heberden Society for 1953, the initials of Dr. Ernest Fletcher should appear as E.T.D. (not E.G.E.). 